\title{
Mycobacterium tuberculosis infection in cattle from the Eastern Cape Province of South Africa
}

\author{
Tiny Motlatso Hlokwe ${ }^{1 *}$, Halima Said ${ }^{2}$ and Nomakorinte Gcebe ${ }^{1}$
}

\begin{abstract}
Background: Mycobacterium tuberculosis is the main causative agent of tuberculosis (TB) in human and Mycobacterium bovis commonly causes tuberculosis in animals. Transmission of tuberculosis caused by both pathogens can occur from human to animals and vice versa.

Results: In the current study, M. tuberculosis, as confirmed by polymerase chain reaction (PCR) using primers targeting 3 regions of difference (RD4, RD9 and RD12) on the genomes, was isolated from cattle originating from two epidemiologically unrelated farms in the Eastern Cape (E.C) Province of South Africa. Although the isolates were genotyped with variable number of tandem repeat (VNTR) typing, no detailed epidemiological investigation was carried out on the respective farms to unequivocally confirm or link humans as sources of TB transmission to cattle, a move that would have embraced the 'One Health' concept. In addition, strain comparison with human M. tuberculosis in the database from the E.C Province and other provinces in the country did not reveal any match.

Conclusions: This is the first report of cases of M. tuberculosis infection in cattle in South Africa. The VNTR profiles of the M. tuberculosis strains identified in the current study will form the basis for creating M. tuberculosis VNTR database for animals including cattle for future epidemiological studies. Our findings however, call for urgent reinforcement of collaborative efforts between the veterinary and the public health services of the country.
\end{abstract}

Keywords: Mycobacterium tuberculosis, Cattle (Bos taurus), Genotyping, Zoonosis

\section{Background}

Mycobacterium tuberculosis and Mycobacterium bovis are the most commonly encountered members of the Mycobacterium tuberculosis complex (MTBC) species worldwide. The former is the main causative agent of $\mathrm{TB}$ in humans, and the latter is responsible for the disease mainly in animals $[1,2]$. Transmission of tuberculosis caused by both pathogens can occur from human to animals and vice versa [3-6]. M. tuberculosis does not appear to have an indigenous animal maintenance host and the animals that become infected represent most probably incidental host [7]. Not much is known about the prevalence of $M$. tuberculosis in its spill over hosts. M. tuberculosis infected animals including cattle react

\footnotetext{
* Correspondence: HlokweT@arc.agric.za

${ }^{1}$ Tuberculosis Laboratory, Diagnostic Services Programme,

ARC-Onderstepoort Veterinary Research, Private Bag X05, Onderstepoort,

Pretoria 0110, South Africa

Full list of author information is available at the end of the article
}

positively when subjected to tuberculin skin testing (TST); however, the infection seems to vanish rather quickly and does not normally lead to a progressive disease [7-9]. M. tuberculosis infections in cattle is known to occur mostly in countries with the highest incidences of human tuberculosis in Africa and Asia [10]. The prevalence of $M$. tuberculosis infections in cattle in isolated studies was reported to be $6.2 \%$ in Algeria [11], $7.4 \%$ in Sudan [12], $7 \%$ and approximately $27 \%$ in different studies conducted in Ethiopia [13, 14]. It should however, be noted that these prevalence was only for isolated studies and do not reflect the individual country's true prevalence. In a study conducted in Nigeria, $M$. tuberculosis was isolated from cattle that reacted positive to caudal fold intradermal tuberculin test (bovine tuberculin test). The cattle attendant was also diagnosed with active pulmonary tuberculosis. Although genotyping of the isolates was not conducted, the cattle 
attendant was suggested to be the most probable source of $M$. tuberculosis in cattle [15].

In South Africa, TB in cattle is known to be caused by $M$. bovis. Control strategies have already been in place since 1969, and reduced the disease prevalence to less than $1 \%$, although sporadic outbreaks still occur $[16,17]$. On the contrary, our country was amongst the six countries with the highest incidence of human $\mathrm{TB}$, with the estimated incidence of 450,000 cases of active disease reported in 2013 [18]. According to the South African government, $73 \%$ of these TB patients were co-infected with HIV (Human Immunodeficiency Virus). Multidrug resistant (MDR) and extensively drug-resistant (XDR) strains of $M$. tuberculosis occur, with some strains linked to high mortality rate [19] and some suggested to be hyper virulent with greater ability to evade host defences [20]. Investigators in several countries have traced the sources of $M$. tuberculosis on cattle farms as humans with active TB [10, 14, 21]. Tracing of sources of infections is mainly achieved by conducting molecular typing techniques to establish the epidemiological relatedness of the strains from both cattle and humans [6, 21]. Transmission to cattle usually occurs via sputum but rarely urine and faeces of infected individuals [22].

We report in the current study, the infection of cattle with M. tuberculosis in two cases from different farms in the Eastern Cape (E.C) Province of South Africa (S.A). Our work is first to report M. tuberculosis infections in cattle in South Africa. M. tuberculosis is zoonotic and some strains are known to be highly virulent. As such, infection in cattle is a public health concern since there is a risk of spill back to humans, especially in immunocompromised individuals. We found it imperative to conduct molecular characterization of the cattle strains in an attempt to elucidate sources of infection by comparison with those in the local human data base. The genotyping profiles generated in the study will form the basis for creation of a database for future epidemiological studies of $M$. tuberculosis infections in animals including cattle.

\section{Results}

Acid-fast organisms were isolated from a lung sample (TB 7000; animal ID 25545); and prescapsular (TB 6985A) and mesenteric (TB 6985B) lymph nodes (animal ID 83750233) from cattle originating from farm 1 . On farm 2, isolation was made from a prescapsular lymph node (TB 7046A; animal ID 84750367) and from a mediastinal lymph node (TB 7047; animal ID 23738). No visible tuberculous lesions were observed in any of these samples (Table 1). Two mycobacterial isolates (i.e. TB 7000 and TB 7046A), one from each farm, were confirmed as members of the Mycobacterium tuberculosis complex (MTBC) species by PCR amplification of the
MTBC specific 372 bp product. No PCR product was observed for the other acid-fast bacteria. Deletion analysis PCR using primers targeting individual regions of differences RD4 (172 bp product), RD9 (235 bp product) and RD12 (369 bp product) identified the isolates as $M$. tuberculosis (Figs. 1, 2, 3 and 4). The other three isolates that tested negative on the MPB70 PCR were identified as Mycobacterium nonchromogenicum (TB 6985A and TB 6985B) and a non-tuberculous mycobacterium (NTM) species closely related to Mycobacterium moriokaense by $16 \mathrm{~S}$ rDNA polymerase chain reaction (PCR) and sequence analysis. Information regarding all samples cultured and the Mycobacterium species isolated is presented in Table 1.

We compared the cattle $M$. tuberculosis strains VNTR profiles (Table 2) to those of humans available in the database at the National Institute of Communicable Disease (NICD) and found no match to any of the human VNTR profiles from the Eastern Cape Province as well as other provinces. According to the phylogenetic tree (Fig. 5), which was constructed using VNTR data from cattle and human strains identical at 5-10 VNTR loci, no genetic relatedness amongst the strains could be established.

\section{Discussion}

In this study, we have isolated and identified M. tuberculosis from two cattle originating from two epidemiologically unrelated farms in the Eastern Cape Province of South Africa. The use of genomic regions of difference (i.e. RD4; RD9 and RD12) as described by Warren and co-workers [23] was useful in the correct identification of the isolates since both bovine and human tuberculosis have been previously detected in the country [17; 19]. According to Biet and co-workers, the route of $\mathrm{TB}$ transmission can be determined by observing the pattern or location where lesions are found in slaughtered animals [24]. Nonetheless, in the current report, no visible tuberculous lesions were observed in the cattle samples processed in both cases, and these observations corroborated previous findings from other studies $[6,10,25]$. Indeed, the severity of pathology in cattle infected with $M$. tuberculosis has been found to be lower compared to that of cattle infected with M. bovis [3], which explains the absence of lesions in these cases. In addition, cattle were also previously thought to be quite resistant to $M$. tuberculosis infection [24]. Our findings further supports a previous report which highlighted the importance of collecting samples from tissues prone to tuberculosis infection even where there are no visible lesions from animals that reacted positive on tuberculin skin test as M. tuberculosis may be isolated from such samples [23]. Isolation of $M$. tuberculosis species from a lung and a prescapsular lymph node from the two cases respectively 
Table 1 Animal identification, culture results and identification of Mycobacterium species isolated from tissue samples of cattle originating from two different farms in the Eastern Cape Province of South Africa

\begin{tabular}{|c|c|c|c|c|c|c|}
\hline $\begin{array}{l}\text { Laboratory } \\
\text { identification }\end{array}$ & $\begin{array}{l}\text { Animal } \\
\text { identification }\end{array}$ & Sample type & $\begin{array}{l}\text { Laboratory macroscopic } \\
\text { examination of lesions }\end{array}$ & Culture results & $\begin{array}{l}\text { Mycobacterium } \\
\text { species identification }\end{array}$ & Farm \\
\hline TB 6982 & 83750230 & Mesenteric lymph node & Absent & Negative & N/A & Farm 1 \\
\hline TB 6983 & 83750231 & Prescapsular lymph node & Absent & Negative & N/A & Farm 1 \\
\hline TB 6984 & 83750232 & Mesenteric lymph node & Absent & Negative & N/A & Farm 1 \\
\hline TB 6985A & 83750233 & Prescapsular lymph node & Absent & Positive & M. nonchromogenicum & Farm 1 \\
\hline TB 6985B & 83750233 & Mesenteric lymph node & Absent & Positive & M. nonchromogenicum & Farm 1 \\
\hline TB 6986 & 83750234 & Bronchial lymph node & Absent & Negative & N/A & Farm 1 \\
\hline TB 6987 & 83750237 & Prescapsular lymph node & Absent & Negative & N/A & Farm 1 \\
\hline TB 6988 & 83750239 & Prescapsular lymph node & Absent & Negative & N/A & Farm 1 \\
\hline TB 6889 & 83750219 & Prescapsular lymph node & Absent & Negative & N/A & Farm 1 \\
\hline TB 6990 & 83750221 & Mesenteric lymph node & Absent & Negative & N/A & Farm 1 \\
\hline TB 6991 & 83750224 & Mesenteric lymph node & Absent & Negative & N/A & Farm 1 \\
\hline TB 6992 & 83750226 & Prescapsular lymph node & Absent & Negative & N/A & Farm 1 \\
\hline TB 6993 & 83750227 & Prescapsular lymph node & Absent & Negative & N/A & Farm 1 \\
\hline TB 6994 & 83750228 & Prescapsular lymph node & Absent & Negative & N/A & Farm 1 \\
\hline TB 6995 & 83750229 & Prescapsular lymph node & Absent & Negative & N/A & Farm 1 \\
\hline TB 6996 & 83750235 & Mesenteric lymph node & Absent & Negative & N/A & Farm 1 \\
\hline TB 6997 & 83750236 & Bronchial lymph node & Absent & Negative & N/A & Farm 1 \\
\hline TB 6998 & 83750240 & Lung & Absent & Negative & N/A & Farm 1 \\
\hline TB 6999 & 83750242 & Prescapsular lymph node & Absent & Negative & N/A & Farm 1 \\
\hline TB 7000 & 25545 & Lung & Absent & Positive & M. tuberculosis & Farm 1 \\
\hline TB 7044 & 84750360 & Mediastinal lymph node & Absent & Negative & N/A & Farm 2 \\
\hline TB 7045 & 84750366 & Mesenteric lymph node & Absent & Negative & N/A & Farm 2 \\
\hline TB 7046 & 84750367 & Prescapsular lymph node & Absent & Positive & M. tuberculosis & Farm 2 \\
\hline TB 7047 & 23738 & Mediastinal lymph node & Absent & Positive & $\begin{array}{l}\text { NTM species closely } \\
\text { related to M. moriokaense }\end{array}$ & Farm 2 \\
\hline TB 7048 & 84750345 & Mediastinal lymph node & Absent & Negative & N/A & Farm 2 \\
\hline TB 7049 & 84750359 & Mediastinal lymph node & Absent & Negative & N/A & Farm 2 \\
\hline TB 7050 & 84750346 & Bronchial lymph node & Absent & Negative & N/A & Farm 2 \\
\hline TB 7051 & 84750334 & Bronchial lymph node & Absent & Negative & N/A & Farm 2 \\
\hline TB 7052 & 84750349 & Bronchial lymph node & Absent & Negative & N/A & Farm 2 \\
\hline
\end{tabular}

NTM Non-tuberculous mycobacterium, N/A Not applicable

may suggest erogenous transmission [26]. We suspect humans suffering from active tuberculosis as possible sources of infection through close contact with the cattle. This may not be surprising since our country has a high incidence of tuberculosis infection in humans [18]. Ideally, to unequivocally confirm or link humans as sources of the M. tuberculosis infections, the disease status of humans on the respective farms should be investigated. Unfortunately, this important action could not be carried out at the time, a move that would have embraced the concept of 'One Health'. However, the genotypes from the cattle strains of $M$. tuberculosis were compared to those from local and national human data bases at the National Institute of Communicable
Diseases (NICD) and no genetic relatedness amongst the strains could be established. These findings suggest lack of epidemiological relationship between the cattle strains and those available in the databases. Nonetheless, the VNTR profiles identified in the current study will form the basis for creating a genotyping database for animal M. tuberculosis strains for future epidemiological studies in South Africa.

Although M. tuberculosis infections is a problem in humans in our country, the prevalence in cattle is not known since no prevalence studies have been published so far. Additionally, for all cases of bovine tuberculosis confirmations done by the Tuberculosis laboratory of ARC-Onderstepoort Veterinary Research, which is a 


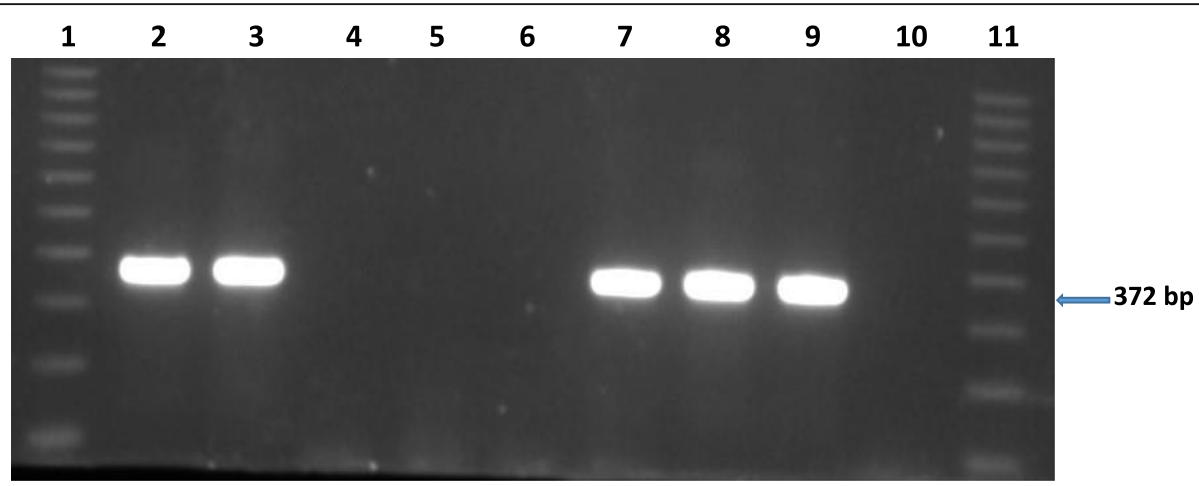

Fig. 1 Gel electrophoresis results of the Polymerase Chain Reaction (PCR) products for the identification of Mycobacterium tuberculosis complex bacteria. Lane 1 and 11, molecular weight marker (100 bp ladder). Lane 2, TB 7000; lane 3, TB 7046A; lane 4, TB 6985A; lane 5, TB 6985B; lane 6, TB 7047, lane 7-8, Mycobacterium bovis in house controls; lane 9, Mycobacterium tuberculosis $\mathrm{H} 37 \mathrm{Rv}$ control; lane 10, $\mathrm{H}_{2} \mathrm{O}$ control. bp = base pairs

national bovine tuberculosis laboratory for surveillance and control purposes, only $M$. bovis was detected from all other cattle cases. To the best of our knowledge, our findings represent the first reported cases of $M$. tuberculosis infections in cattle in South Africa, however, cases of M. tuberculosis in captive wildlife have been reported. In these reports, humans were suspected as possible sources of infections [27, 28]. Both incidences of $M$. tuberculosis infections in cattle and in captive wildlife species pose a threat of spill back to humans since these animal species and humans are in most cases in close contact and direct transmission may occur. In a study conducted in Ethiopia, although investigators could not identify any transmission of M. tuberculosis between human and cattle, they suspected that the local practice of chewing tobacco and spitting into the mouths of cattle with the purpose of enhancing animal performance may have played a role in the transmission of $M$. tuberculosis to cattle, suggesting transmission by ingestion [3, 14]. In addition, they speculated that cattle became infected

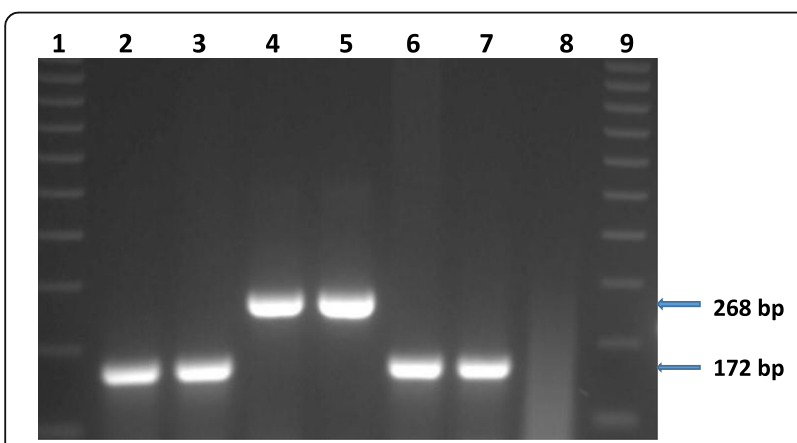

Fig. 2 Gel electrophoresis results of the RD4 Polymerase Chain Reaction (PCR) products for the identification of Mycobacterium tuberculosis Lane 1 and 9, molecular weight marker (100 bp ladder). Lane 2, TB 7000; lane 3, TB 7046A; lane 4-5, Mycobacterium bovis in house controls; lane 6, Mycobacterium tuberculosis in house control; lane 7, Mycobacterium tuberculosis H37Rv control; lane 8, $\mathrm{H}_{2} \mathrm{O}$ control. bp = base pairs through aerosol inhalation from human while brought into the farmer's house at night [3].

We have also isolated non-tuberculous Mycobacterium (NTM) species, Mycobacterium nonchromogenicum, from a prescapsular and mesenteric lymph node of a cow on farm 1, and an NTM species closely related to Mycobacterium moriokaense from a mediastinal lymph node of a cow on the other farm. Similar to isolation of M. tuberculosis, the NTM species were also detected from samples without visible lesions and therefore their clinical significance could not be determined in this study. However, their isolation from cattle which were suspects or reacted positively upon tuberculin skin testing is not surprising since some NTM species are known to cross react against $M$. bovis antigens in tuberculin based TB tests. Indeed, Gcebe and co-workers found shared antigens between $M$. bovis and M. nonchromogenicum using comparative genomics and proteomics approaches [29]. Additionally, in their follow up study to evaluate the immunogenicity of a purified protein derivative (PPD) prepared from M. nonchromogenicum, they found that indeed $M$. nonchromogenicum does elicit an immune response which is cross reactive against $M$. bovis antigens using routine diagnostic samples from cattle and African buffaloes (Syncerus caffer) in a modified gamma interferon assay (Gcebe et al., unpublished). Furthermore, $M$. nonchromogenicum was previously found to be amongst the four prevalent species in South African cattle, buffaloes and their environments [30].

\section{Conclusion}

The cases described in this paper highlight $M$. tuberculosis as a zoonotic threat and a significant veterinary and an ongoing public health challenge in our country. The study reinforces the need for collaborative efforts between the veterinary and the public health services to ensure that detailed epidemiological investigations are carried out in cases such as these. 


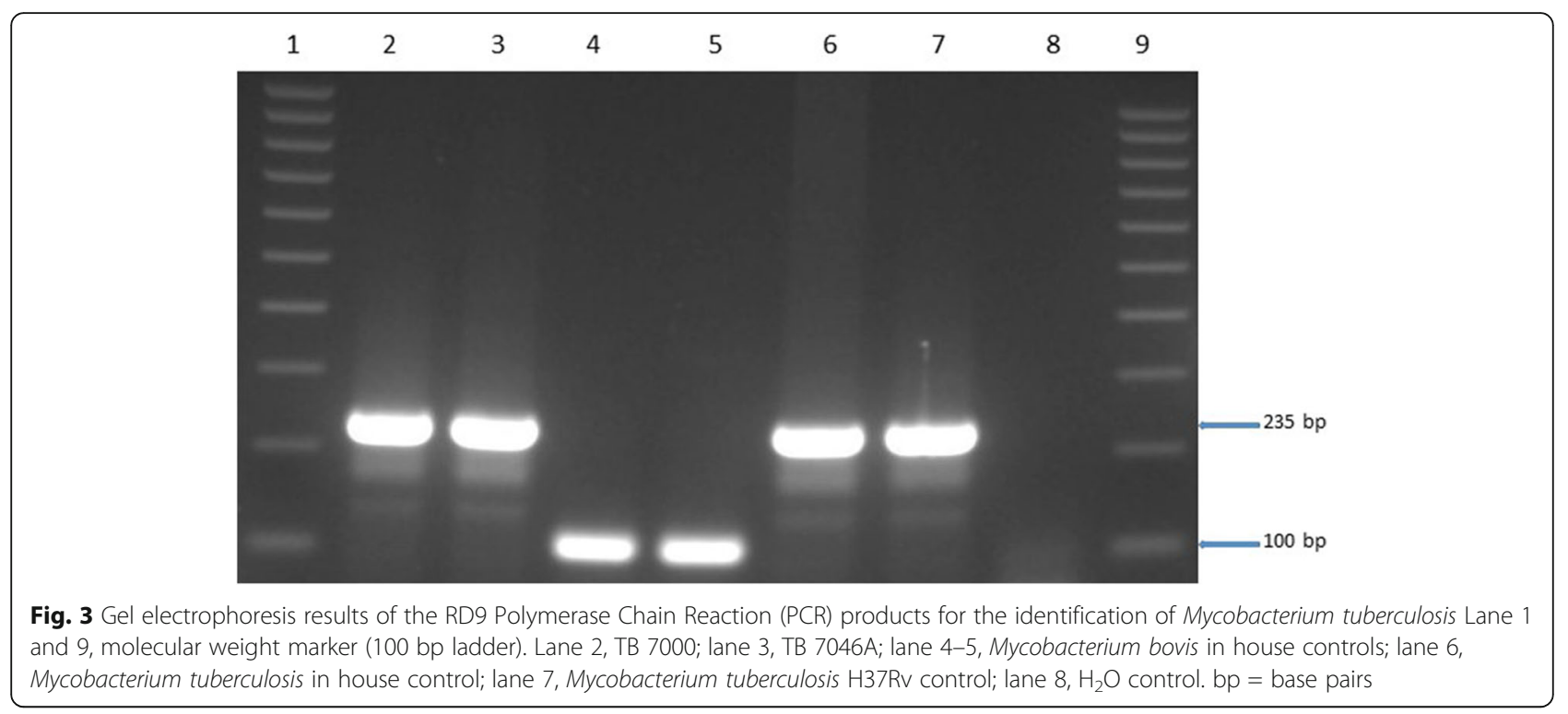

\section{Methods}

\section{Tissue samples and Mycobacterium species cultivation}

In 2008, tissue samples from cattle originating from two epidemiologically unrelated commercial farms (farm 1; $n=20$, from 19 animals, and farm $2 ; n=9$, from 9 animals) located in the E.C Province of S.A were submitted to the Tuberculosis Laboratory at the Agricultural Research Council-Onderstepoort Veterinary Research (ARC-OVR) for routine Mycobacterium species isolation. M. bovis infection was previously detected from cattle on farm 1 [17], however, the bovine tuberculosis status on farm 2 was unknown. Routine submissions at the Tuberculosis laboratory of the ARC-OVR form part of the State Veterinary Service's strategy for confirming tuberculosis infections in either skin test positive/suspect reactor or slaughter cattle with suspect tuberculous lesions. In these two cases, suspect or positive reactor cattle were slaughtered and sampled subsequent to a comparative intradermal tuberculin testing using bovine and avian PPD (Prionics, Lelystad) conducted by a local State Veterinarian. No information was provided on the sample submission form, which accompanied the samples, regarding the total number of animals, tested using the intradermal skin test. Bovine tuberculosis is a controlled disease in South Africa according to the animal disease legislation act 35 of 1984. Handling of animals during slaughter and sampling was done by professional Animal Health Technicians and State Veterinarians according to their procedures, and no animal ethics approval was required. Predilection sites prone to TB infection were sampled (Table 1). In the laboratory, tissue samples to be processed for mycobacterial isolation were carefully examined macroscopically for formation of suspected tuberculous-like lesions (visible). The presence or absence of suspect TB-like lesion was recorded for each sample (Table 1). The samples were processed and cultured according to standard laboratory procedures. Briefly, approximately $5 \mathrm{~g}$ of tissue samples were cut

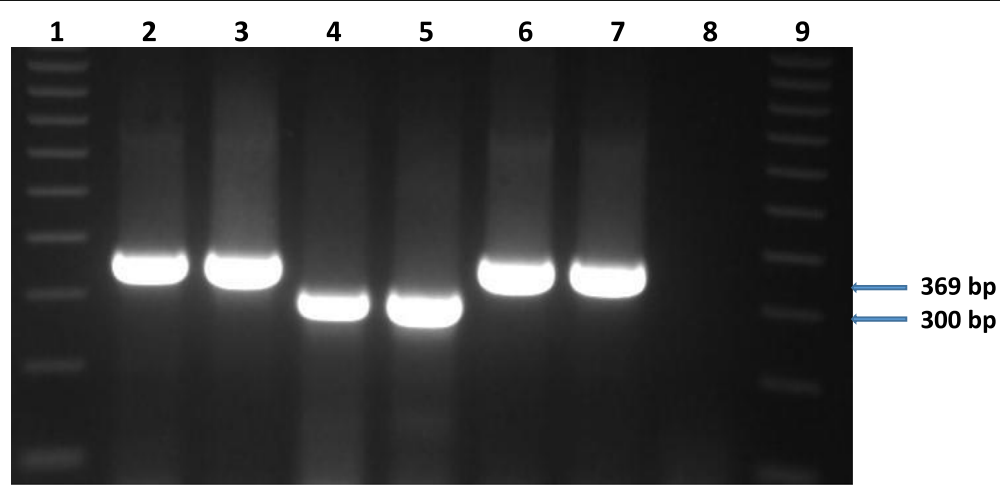

Fig. 4 Gel electrophoresis results of the RD12 polymerase chain reaction (PCR) products for the identification of Mycobacterium tuberculosis Lane 1 and 9, molecular weight marker (100 bp ladder). Lane 2, TB 7000; lane 3, TB 7046A; lane 4-5, Mycobacterium bovis in house controls; lane 6, Mycobacterium tuberculosis in house control; lane 7, Mycobacterium tuberculosis $\mathrm{H} 37 \mathrm{Rv}$ control; lane $8, \mathrm{H}_{2} \mathrm{O}$ control. bp = base pairs 


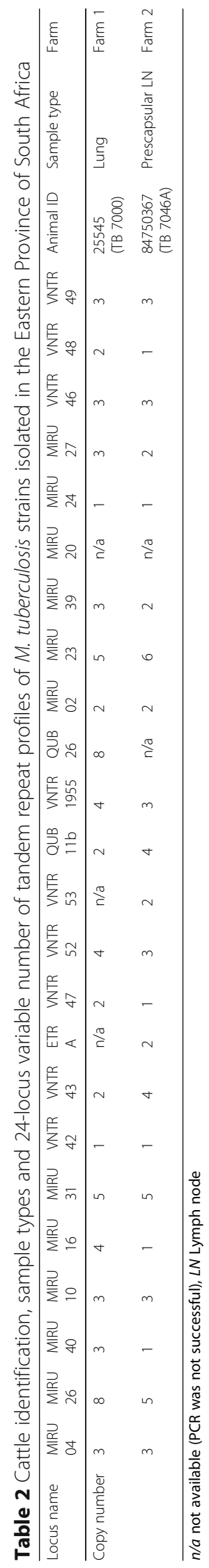




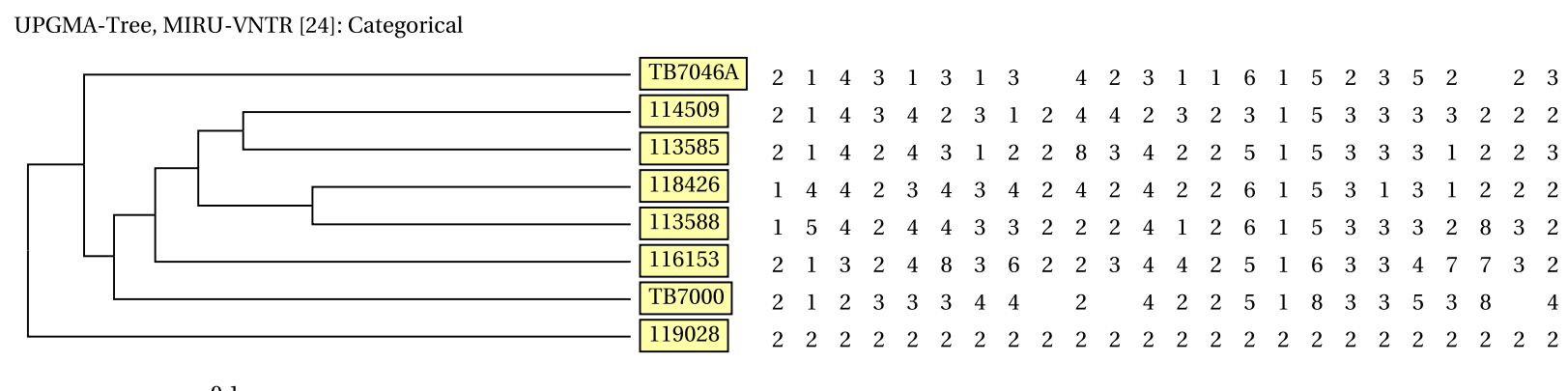

Fig. 5 Phylogenetic tree based on a 24 variable number of tandem repeat (VNTR) data illustrating the genetic relationship of the cattle M. tuberculosis strains in comparison to a selection of human M. tuberculosis strains in the National Institute of Communicable Diseases (NICD) human database for strains identical at 5-10 VNTR loci originating from different regions in South Africa. The human isolates originated from the KwaZulu-Natal and North West Provinces of South Africa

into small pieces and covered with $100 \mathrm{ml}$ of sterile distilled water in a biohazard cabinet (Esco Class II BSC; Labotec, SA). The samples were homogenized using the UltraTurrax $^{\bullet}$ homogenizer (Separation Scientific, SA). Seven millilitres of the homogenates were poured into two separate $15 \mathrm{ml}$ falcon tubes, and decontaminated with $7 \mathrm{ml}$ of $2 \% \mathrm{HCL}$ and $7 \mathrm{ml}$ of $4 \% \mathrm{NaOH}$ for $10 \mathrm{~min}$. Following centrifugation at $2360 \mathrm{~g}$ for $10 \mathrm{~min}$ (Labofuge 400, Haraeus Instruments), the supernatant was discarded and sterile distilled water was added to the pellet. The centrifugation step was repeated and the supernatant was discarded. The pellet was inoculated onto Löwenstein-Jensen (L-J) media slopes supplemented with glycerol and pyruvate; which are known to promote growth of mycobacteria; and incubated at $37^{\circ} \mathrm{C}$ for up to 10 weeks with weekly monitoring.

\section{Ziehl Neelsen staining}

Bacterial growth observed during monitoring was subjected to Ziehl Neelsen (ZN) staining to check for acid-fast bacteria (AFB). Bacterial smears were prepared from colonies on a microscopic slide. The stained slides were viewed under a microscope for AFB.

\section{Preparation of mycobacterial cell lysate}

Cell lysates of acid-fast bacteria were prepared by picking up larger individual colonies or several small colonies from the L-J media. Bacteria were suspended in $100 \mu \mathrm{l}$ sterile distilled water. The suspensions were boiled at $100{ }^{\circ} \mathrm{C}$ for $25 \mathrm{~min}$, cooled down to room temperature and then transferred either $4{ }^{\circ} \mathrm{C}$ (short term storage) or $-20{ }^{\circ} \mathrm{C}$ for long term storage [31].

\section{Identification of Mycobacterium tuberculosis complex species by PCR}

Acid-fast isolates were subjected to amplification by PCR to identify MTBC bacteria using primers that target a sequence encoding the MPB70 antigen [32]. For each AFB isolate, a 50 ul PCR reaction was prepared containing the following components: $25 \mu \mathrm{l}$ Ultra-pure water; $5 \mu$ of $10 \mathrm{X}$ reaction buffer (Separation Scientific), $3 \mu \mathrm{l}$ of $25 \mathrm{mM} \mathrm{MgCl}_{2}$ (Separation Scientific); $2.5 \mu \mathrm{l}$ of $1 \mathrm{mM}$ dNTP (Inqaba Biotechlonogies Industries); $2 \mu \mathrm{l}$ of $20 \mathrm{pMol} / \mathrm{ul}$ TB1A forward primer (5' GAACAATCCGGAGTTGACAA 3'); $2 \mu \mathrm{l}$ of $20 \mathrm{pMol} / \mathrm{ul}$ TB1B reverse primer (5' AGCACGCTGTCAATCATGTA 3') (Inqaba Biotechlonogies Industries) and $0.5 \mu \mathrm{l}$ of SuperTherm Taq polymerase (Separation Scientific). The master mix was well mixed while avoiding bubbles and $39 \mu \mathrm{l}$ of it was aliquoted into pre labelled micro centrifuge tubes as well as $10 \mu \mathrm{l}$ of the template DNA (bacterial lysate). The PCR cycling parameters were as follows: initial denaturation at $94{ }^{\circ} \mathrm{C}$ for $5 \mathrm{~min}$, next, each cycle consisted of denaturation at $94{ }^{\circ} \mathrm{C}$ for $30 \mathrm{~s}$; annealing at $64{ }^{\circ} \mathrm{C}$ for $30 \mathrm{~s}$, elongation at $72{ }^{\circ} \mathrm{C}$ for 2 min (40 cycles) and holding at $4{ }^{\circ} \mathrm{C}$. PCR amplification was carried out using an Eppendorf AG 22331 Hamburg thermo cycler (Merck). The PCR products were separated on a $1.5 \%$ agarose gel stained with $20 \mu \mathrm{l}$ ethidium bromide $(10 \mu \mathrm{g} / \mathrm{ml})$ and run at $80 \mathrm{~V}$ for $3 \mathrm{~h}$. A $100 \mathrm{bp}$ ladder (Inqaba Biotechnical Industries) was included. A product size of $372 \mathrm{bp}$ was expected for MTBC species.

\section{Identification of Mycobacterium tuberculosis by PCR}

For each MTBC isolate, a PCR reaction contained $5 \mu \mathrm{l}$ 10X-buffer (Separation Scientific); $2 \mu \mathrm{l} 25 \mathrm{mM} \mathrm{MgCl} 2$ (Separation Scientific); $4 \mu \mathrm{l}$ of $10 \mathrm{mM}$ dNTP (Inqaba Biotechnologies); $0.5 \mu \mathrm{l}$ of $50 \mathrm{pmol} / \mu \mathrm{l}$ of either RD4; RD9 and RD12 primers (Inqaba Biotechnologies) (RD 4 forward $=5^{\prime}$-ATGTGCGAGCTGAGCGATG-3'; RD4 internal $=5^{\prime}$-TGTACTATGCTGACCCATGCG-3' and RD4 reverse $=5^{\prime}$-AAAGGAGCACCATCGTCCAC-3; RD9 forward: 5'-CAAGTTGCCGTTTCGAGCC-3'; RD9 internal: 5' -CAATGTTTGTTGCGCTGC-3'; RD9 reverse: 5'GCTACCCTCGACCAAGTGTT-3'; RD12 forward: 5'-GGGAGCCCAGCATTTACCTC-3'; RD12 internal: 5'GTGTTGCGGGAATTACTCGG-3'; RD12 
reverse: 5' -AGCAGGAGCGGTTGGATATTC-3'); $0.4 \mu \mathrm{l}$ SuperTherm DNA polymerase (Separation Scientific) and $2 \mu \mathrm{l}$ DNA template. The mixture was made up to $25 \mu \mathrm{l}$ with sterile distilled water. PCR amplifications were carried out for individual primer sets as follows: initial denaturation at $94{ }^{\circ} \mathrm{C}$ for $15 \mathrm{~min}$, followed by 45 cycles at $94{ }^{\circ} \mathrm{C}$ for $1 \mathrm{~min}$; annealing at $62{ }^{\circ} \mathrm{C}$ for $1 \mathrm{~min}$; elongation at $72{ }^{\circ} \mathrm{C}$ for $1 \mathrm{~min}$. After the last cycle, the samples were incubated at $72{ }^{\circ} \mathrm{C}$ for $10 \mathrm{~min}$. PCR amplification was carried out using an Eppendorf AG 22331 Hamburg thermo cycler (Merck). The PCR products were separated on a $2 \%$ agarose gel stained with $20 \mu \mathrm{l}$ ethidium bromide $(10 \mu \mathrm{g} /$ $\mathrm{ml}$ ) and run at $80 \mathrm{~V}$ for $3 \mathrm{~h}$. A $100 \mathrm{bp}$ ladder (Inqaba Biotechnical Industries) was included. Product sizes of 172 bp, 235 bp and 369 bp for RD4, RD9 and RD12 respectively, were expected [23].

\section{Identification of non-tuberculous mycobacteria}

Non-tuberculous mycobacteria (NTM) were identified by PCR and sequence analysis of the $577 \mathrm{bp}$ of the Mycobacterium species $16 \mathrm{~S}$ rDNA. PCR targeting a 577 bp fragment of mycobacterial $16 \mathrm{~S}$ rDNA was performed using the primers: $16 \mathrm{~S}-\mathrm{F}$ (5'-AGA GTT TGA TCM TGG CTCAG-3') and 16S-R (5'-GCG ACA AAC CAC CTA AGA G-3'). Culture suspensions were used as DNA template in a $25 \mu \mathrm{l}$ PCR mixture containing $12.9 \mu \mathrm{l}$ deionized water, $2.5 \mu \mathrm{l}$ of $10 \mathrm{X}$ PCR buffer $(160 \mathrm{mM})$ (Tris $\left.\mathrm{Cl}, \mathrm{KCl},\left(\mathrm{NH}_{4}\right)_{2} \mathrm{SO} 4\right), 2 \mu \mathrm{l} \quad \mathrm{MgCl}_{2}$ $(25 \mathrm{mM}), 1 \mu \mathrm{l}$ dNTPs $(10 \mathrm{mM}), 0.1 \mu \mathrm{l}$ Taq polymerase (Qiagen Hotstar Taq, Whitehead Scientific, South Africa), $5 \mu \mathrm{l}$ of $5 \times$ Q-solution, $1 \mu \mathrm{l}$ of each forward and reverse primers $(50 \mathrm{pmol})$ and $1-2 \mu \mathrm{l}$ DNA template. The PCR cycling parameters were as follows: initial denaturation at $95{ }^{\circ} \mathrm{C}$ for $15 \mathrm{~min}$, followed by 35 cycles of denaturation at $95{ }^{\circ} \mathrm{C}$ for $30 \mathrm{~s}$, annealing at $60{ }^{\circ} \mathrm{C}$ for $30 \mathrm{~s}$ and elongation at $72{ }^{\circ} \mathrm{C}$ for $30 \mathrm{~s}$ and a final extension at $72{ }^{\circ} \mathrm{C}$ for $10 \mathrm{~min}$. The amplicons were sent to Inqaba Biotechnologies, South Africa for sequencing of the forward $16 \mathrm{~S}$ rDNA strands using an $\mathrm{ABI}$ sequencer. Sequences were edited manually and pairwise alignments undertaken using the BioEdit Sequence alignment editor (version 7.1.9) and Molecular Evolutionary Genetics Analysis (MEGA) platform [30]. The sequences were then analyzed on the NCBI BLAST platform for species identification by mega blast [25].

\section{Genotyping}

M. tuberculosis isolates were genotyped using a standardized 24 loci variable number of tandem repeat (VNTR) as previously described [33]. The loci were amplified individually as previously described [34, 35]. VNTR typing PCR was performed in a $20 \mu \mathrm{l}$ reaction containing $2 \mu \mathrm{l}$ of DNA, $10 \mu \mathrm{l}$ of the Qiagen master mix, $7 \mu \mathrm{l}$ of DNA free water and $0.5 \mu \mathrm{l}$ of each $20 \mathrm{pM}$ primer.
The cycling parameters were as follows: initial denaturation at $94{ }^{\circ} \mathrm{C}$ for $5 \mathrm{~min}$, followed by 40 cycles of denaturation at $94{ }^{\circ} \mathrm{C}$ for $1 \mathrm{~min}$, annealing at $62{ }^{\circ} \mathrm{C}$ for $1 \mathrm{~min}$, elongation at $72{ }^{\circ} \mathrm{C}$ for $1.5 \mathrm{~min}$ and a final elongation step at $72{ }^{\circ} \mathrm{C}$ for $10 \mathrm{~min}$. PCR was carried out using an Eppendorf AG 22331 Hamburg thermo cycler (Merck). The PCR products were separated on a $2 \%$ agarose gel stained with $20 \mu \mathrm{l}$ ethidium bromide $(10 \mu \mathrm{g} /$ $\mathrm{ml}$ ) and run at $80 \mathrm{~V}$ for $3 \mathrm{~h}$. A $100 \mathrm{bp}$ ladder (Inqaba Biotechnical Industries) was included and used to estimate the sizes of the resulting PCR products. The VNTR profiles were recorded as a series of numbers corresponding to the number of alleles at each locus (Table 2) and were compared to human VNTR profile database (from the Eastern Cape Province and other provinces) at the National Institute of Communicable Diseases. From the entire database, we selected those human M. tuberculosis strains, which were identical to the cattle strains at 5-10 VNTR loci for construction of a dendrogram [36]. The dendrogramme was constructed using the MIRU-VNTRplus database (www.miru-vntrplus.org/). The results were entered into the database as numerical codes corresponding to the number of alleles at each locus. The categorical coefficient was used to calculate the distance matrix and the dendrogramme was constructed using the Unweighted Pair Group Method with Arithmetic averages (UPGMA) algorithm.

\section{Acknowledgements}

We thank our colleagues Dr. Jeanni Fehrsen and Mr. I-Chang Lee for reviewing the manuscript.

\section{Funding \\ The Agricultural Research Council-Onderstepoort Veterinary Research funded} this work.

\section{Availability of data and materials \\ All data generated or analyzed in this current study are available in the} manuscript.

\section{Authors' contributions}

Conceived and designed experiments: TM N. Performed experiments: TM N. Analyses and interpreted results: TM N H. Writing of original manuscript draft: TM. Review and editing of manuscript drafts: TM N H. All authors read and approved the final manuscript.

Ethics approval and consent to participate Not applicable.

Consent for publication

Not applicable.

Competing interests

The authors declare that they have no competing interests.

\section{Publisher's Note}

Springer Nature remains neutral with regard to jurisdictional claims in published maps and institutional affiliations.

\section{Author details}

${ }^{1}$ Tuberculosis Laboratory, Diagnostic Services Programme,

ARC-Onderstepoort Veterinary Research, Private Bag X05, Onderstepoort, 
Pretoria 0110 , South Africa. ${ }^{2}$ Division of the National Health Laboratory Services, Centre for Tuberculosis, National Institute for Communicable Diseases, Private Bag X4, Sandringham, Johannesburg, South Africa.

Received: 3 May 2017 Accepted: 3 October 2017

Published online: 10 October 2017

\section{References}

1. Pavlik I, Ayele W, Havelkova M, Svejnochova M, Katalinic-Jankovic V, ZolnirDovc M. Mycobacterium bovis in human population in four central European countries during 1990 to 1999. Vet Med-Czech. 2003:48(Suppl 4):90-8.

2. Smith NH, Gordon SV, De la Rua-Domenech R, Clifton-Hadley RS, Hewinson RG. Bottlenecks and broomsticks: the molecular evolution of Mycobacterium bovis. Nat Rev Microbiol. 2006;4:670-81.

3. Ameni GK, Tadesse E, Hailu Y, Deresse Y, Medhin G, Aseffa A, Hewinson G, Vordemeier M, Berg S. Transmission of Mycobacterium tuberculosis between farmers and cattle in Ethiopia. PLoS ONE. 2013;8(Suppl 10):e76891. 10.137/ journal.pone.0076891.

4. Frietsche A, Engel R, Buhl D, Zellweger JP. Mycobacterium bovis tuberculosis: from animal to man and back. Int J of Tuberc Lung Dis. 2004:8:903-4.

5. Michalak K, Austin C, Diesel S, Bacon MI, Zimmerman P, Maslow JN. Mycobacterium tuberculosis infection as a zoonotic disease: transmission between humans and elephants. Emerg Infect Dis. 1998;4:283-7.

6. Ocepek M, Pate M, Žolnir-Dovč M, Poljak M. Transmission of Mycobacterium tuberculosis from human to cattle. J Clin Microbiol. 2005;43:3555-7.

7. Thoen CO, Karlison AG, Himes EM. Mycobacterial infections in animals. Rev Infect Dis. 1981;3:960-72

8. Krishnaswami KV, Mani KR. Mycobacterium tuberculosis human is causing zoonotic tuberculosis among cattle. Indian J Public Health. 1983;27(Suppl 2):60-3.

9. Erler W, Martin G, Sachse K, Naumann L, Kahlau D. Molecular fingerprinting of Mycobacterium bovis subspecies caprae isolates from central Europe. J Clin Microbiol. 2004:42(Suppl 5):2234-8.

10. Romero B, Rodríguez S, Bezos J, Díaz R, Copano MF, Merediz I. Humans as sources of Mycobacterium tuberculosis infection in cattle, Spain. Emerg Infec Dis. 2011;17(Suppl 12):2393-5.

11. Boulahbal F, Benelmouffok A, Brahimi K. Role of Mycobacterium tuberculosis in bovine tuberculosis. Arch Inst Pasteur Alger. 1978:53:155-64.

12. Sulieman MSHME. Identification of acid-fast bacteria from caseous lesions in cattle in Sudan. J Vet Med. B. 2002:49:415-8.

13. Berg S, Firdessa R, Habtamu M, Gadisa E, Mengistu A, Yamuah L. The burden of mycobacterial disease in Ethiopian cattle: implications for public health. PLoS One. 2009;4(Suppl 4):e5068. https://doi.org/10.1371/ journal. pone.0005068.

14. Ameni G, Vordermeier M, Firdessa R, Aseffa A, Hewinson G, Gordon S. Mycobacterium tuberculosis infection in grazing cattle in central Ethiopia. Vet J. 2011;188(Suppl 3-4):359-61.

15. Ibrahim S, Abubakar UB, Danbirni S, Usman A, Ballah FM, Kudi AC, Lawson L, Abdulrazak H, Abdulkadir IA. Molecular identification of Mycobacterium tuberculosis transmission between cattle and man: a case report. J Microbiol Exp. 2016:3(Suppl 3):00091.

16. Michel AL, Hlokwe TM, Coetzee ML, Maré L, Connoway L, Rutten VPMG, Kremer K. High Mycobacterium bovis genetic diversity in a low prevalence setting. Vet Microbiol. 2008;126:151-9.

17. Hlokwe TM, Van Helden P, Michel A. Evidence of increasing intra and interspecies transmission of Mycobacterium bovis in South Africa: are we losing the battle? Prev Vet Med. 2014;115:10-7

18. Who, 2013. Global Tuberculosis Control.

19. Gandhi NR, Brust JCM, Moodley P, Weissman D, Heo M, Ning Y, Moll AP, Friedland $\mathrm{GH}$, Sturm AW, Shah NS. Minimal diversity of drug-resistant Mycobacterium tuberculosis strains in South Africa. Emerg Infect Dis. 2014;20:426-33.

20. Hanekom M, Gey van Pittius NC, McEvoy C, Victor TC, Van Helden PD, Warren RM. Mycobacterium tuberculosis Beijing genotype: a template for success. Tuberc. 2011;91:510-23.

21. Špičić S, Pate M, Duvnjak S, Katalinić-Janković V, Obrovac D, Deźdek D, Kompes G, Habrun B, Ocepek M, Cvetnić Ž. Molecular epidemiology of Mycobacterium tuberculosis transmission between cattle and man-a case study. Vet Arhiv. 2012;82(Suppl 3):303-10.

22. Thoen CO, Steele JH. Mycobacterium bovis infection in animals and humans. lowa State University Press. lowa USA. 1995:273-9.

23. Warren RM, Gey van Pittius NC, Barnard M, Hasseling A, Engelke E, De Kock M, Gutierrez MC, Chege GK, Victor TC, Hoal EG, Van Helden PD.
Differentiation of Mycobacterium tuberculosis complex by PCR amplification of genomic regions of difference. Int J Tuberc Lung Dis. 2006;10(Suppl 1): $818-22$

24. Biet F, Boschiroli M, Torel M, Guilloteau L. Zoonotic aspects of Mycobacterium bovis and Mycobacterium avium-intracellulare Complex (MAC). Vet Res. 2005;36:411-36.

25. https://blast.ncbi.nlm.nih.gov/Blast.cgi: Accessed: Old version accessed on 03 September 2014.

26. LoBue PA, Enarson DA, Thoen CO. Tuberculosis in human and animals: an overview. Int J Tuberc Lung Dis. 2010;14(Suppl 9):1075-8.

27. Michel AL, Venter L, Espie W, Coetzee ML. Mycobacterium tuberculosis infections in eight species at the National Zoological Gardens of South Africa, 1991 to 2001. J Zoo Wildl Med. 2003:34:364-70.

28. Michel AL, Hlokwe MT, Espie IW, Van Langhout M, Koeppel K, Lane E. Mycobacterium tuberculosis at the human/wildlife interface in a high TB burden country. Transbound Emerg Dis. 2013;60(Suppl 1):46-52.

29. Gcebe, N, Michel, A, Gey van Pittius, NC, Rutten, V. Comparative genomics and proteomic analysis of four nontuberculous Mycobacterium species and Mycobacterium tuberculosis complex: occurrence of shared immunogenic proteins. 2016. Frontiers Microbiol. Doi: $103389 f m i c b ~ 2016.00795$.

30. Gcebe N, Rutten V, Gey Van Pittius NC, Michel A. Prevalence and distribution of non-tuberculous mycobacteria (NTM) in cattle, African buffaloes (Syncerus caffer) and their environments in South Africa. Transbound Emerg Dis. 2013;60:74-84.

31. Hokwe, T.M., Jenkins, A.O., Streicher, E.M, Venter, E.H., Cooper, D., Godfroid, J., Michel, A.L. Molecular characterization of Mycobacterium bovis isolated from African buffaloes (Syncerus caffer) in Hluhluwe-iMfolozi Park in KwaZulu-Natal, South Africa. Onderstepoort J. Vet Res. 2011; 78 Suppl 1: Art. \#232. Doi:104102/ojvrv78i1232. 1-6.

32. Cousins DV, Wilton SD, Francis BR, Gow BL. Use of polymerase chain reaction for rapid diagnosis of tuberculosis. J Clin Microbiol. 1992;30:255-8.

33. Supply P, Allix C, Lesjean S, Cardoso-Oelemann M, Rüsch-Gerdes S, Willery E, Savine E, De Haas P, Van Deutekom H, Roring S, Bifani P, Kurepina N, Kreiswirth B, Sola C, Rastogi N, Vatin V, Gutierrez MC, Fauville M, Niemann S, Skuce R, Kremer K, Locht C, Van Soolingen D. Proposal for standardization of optimized mycobacterial interspersed repetitive unit-variable-number tandem repeat typing of Mycobacterium tuberculosis. J Clin Microbiol. 2006; 44:4498-510.

34. Le Fléche P, Fabre M, Denoeud F, Koeck JL, Vergnaud J-L, Vergnaud G. High resolution, on-line identification of strains from the Mycobacterium tuberculosis complex based on tandem repeat typing. BMC Microbiol. 2002;2:37.

35. Hlokwe TM, Van Helden P, Michel AL. Evaluation of the discriminatory power of variable number of tandem repeat typing of Mycobacterium bovis isolates from southern Africa. Transbound Emerg Dis. 2013;60 (Suppl 1):111-20.

36. Weniger T, Krawczyk J, Supply P, Niemann S, Harmsen D. MIRU-VNTRplus: a web tool for polyphasic genotyping of Mycobacterium tuberculosis complex bacteria. Nucleic Acids Res. 2010; https://doi.org/10.1093/nar/gkq351: W326-331.

\section{Submit your next manuscript to BioMed Central and we will help you at every step:}

- We accept pre-submission inquiries

- Our selector tool helps you to find the most relevant journal

- We provide round the clock customer support

- Convenient online submission

- Thorough peer review

- Inclusion in PubMed and all major indexing services

- Maximum visibility for your research

Submit your manuscript at www.biomedcentral.com/submit 